\title{
Social Media Preferences, Interrelations Between the Social Media Characteristics and Culture: A View of Arab Nations
}

\author{
Asli Cazorla Milla ${ }^{1} \&$ Leonardo Jose Mataruna-Dos-Santos ${ }^{1,2}$ \\ ${ }^{1}$ College of Business Administration, American University in the Emirates, Dubai, United Arab Emirates \\ ${ }^{2}$ Centre for Trust, Peace \& Social Relations, Coventry University, United Kingdom \\ Correspondence: Asli Milla, Dubai Academic City, Block 6-7, COBA-AUE, Dubai, United Arab Emirates - \\ UAE. Tel: 971-444-99-628. E-mail: asli.milla@aue.ae
}

\author{
Received: April 7, 2019 Accepted: May 1,2019 Online Published: May 31, 2019 \\ doi:10.5539/ass.v15n6p71 URL: https://doi.org/10.5539/ass.v15n6p71
}

\begin{abstract}
This article is a pioneering theoretical work as an approach from the perspective of combination of social media characteristics and wisdom of crowds. The aim of this article is to conceptualize the social media channels in terms of their characteristics and to discuss the correlation between social media choices and culture. This paper contributes to social media marketing theory by developing a conceptual approach that explains and offers implications pertaining to the relationship between different social media channels in the age of social media. To do this, the relevant literature has been thoroughly reviewed, and exploratory research method has been used. The study also aims to visualize the effect of cultural differences as aligned with the study of Edward Hall (1967) and Gert Hoftstede (1984). Cultural factors exert a broad and deep influence on social media choices. Arab countries are categorized as high-context culture according to Hall's dimensions. The social media reports, Arab Social Media, conducted by Dubai School of Government of the years from 2013, 2013 and 2017 were analyzed. The limited availability of the literature done on the region has limited the scope and analysis of the research. The paper concludes that social media has its characteristics that interrelate with each other and culture has a moderation effect on the choices of social media.
\end{abstract}

Keywords: high context culture, marketing communication, social media

\section{Introduction}

Mass media has been significantly important for marketing promotion for over years and still has its influence on masses. However, the media is in transformation from traditional to a new one. Social media has proved its effectiveness by numerous statistics. Therefore, the new era of marketing requires being online, up to date and user friendly. The use of social media has rapidly increased in the Arab Region as well as other regions. Facebook, Instagram, Snapchat as well as Twitter are some of the examples of social networking sites used among millennials. The youth in the Arab world are amidst the top groups in when it comes to social media usage. Both businesses and governments are using social media for advertising and informative purposes. It is important to note that both generation $\mathrm{Y}$ and $\mathrm{Z}$ in UAE are using social media daily. While in other parts of the world, social media is more popular amongst young people, in the Arab region there has been many experiments and applications where data from social media is used to understand the consumer behavior, buying patterns and marketing communication tools (Aladwani, 2013; Al-Jenaibi, 2011; Salem, 2017). However, there has not been any research conducted in attempt to correlate the cultural variable of context with the usage of certain social networking sites. The present article fills this gap by identifying the relationship between Hall's theory of context and Hoftstede's theory of cultural dimensions (Hall, 1976; Hoftstede, 1984). Mataruna \& Gama (2017) mentioned that social media became produce fresh contents than newspapers and will overpass TV and radio regarding speed of communication.

Social media is essentially accessible technologies that transform Internet communications in an interactive platform, i.e. smart phones, PCs, tablet computers, portable media, etc. Social media platforms like Facebook, Instagram, WhatsApp and Snapchat are all available from the Web 2.0 (Kaplan \& Haenlein 2010). Social media is termed as those online applications, platforms and media which aim to simplify interactions, collaborations and content sharing. In social media information is created and catered to its users by its users (Sundaram, 2017). 
Milla, Mataruna and Ristic (2018) mention that social media has two main characteristics:

a) Participation: Social media eliminates the distance between followers-listeners and the media by encouraging participation and feedback of the people interested in the media.

b) Openness: Most social media services are open to participation and feedback. These services encourage participants to vote, write comments, and share information.

\section{Research Questions}

The study principally focused on the following questions:

- Is there a correlation within the social media characteristics, culture and the media choices?

- How does this culture effect the practice of social media marketing communication tools in the Arab nations?

\section{Literature Review}

The study of the cultures has been one of the most investigated areas in social sciences. The challenge of studying cultures lies in the ethnocentrism. Cross-cultural studies carried out by Hofstede, Trompeenar and Hall were referred to by more than 10000 researches in the literature. This study particularly focuses on Hall's context and Hoftstede's individualistic vs collectivist dimensions. Edward Hall broke down the cultural patterns in terms of context, time, space and information flow. Hoftstede broke down the cultural patterns in terms of power distance, individuality, time, risk-taking and achievement. Peculiarly, the context dimension is important for understanding advertising and marketing communications across cultures (Mooij, 2018).

\subsection{High Context Vs Low Context Cultures}

Hall described the high context cultures as having a rather implicit, meaning that context and relationships are more important than the actual words. Whereas, in low context cultures, the message is communicated almost entirely by the words and therefore needs to be explicit. In other words, the communication occurs in a fast and efficient manner in high-context cultures compared to low context cultures. In high-context cultures symbols and visuals play a crucial role in the communication. The high and low-context cultures of Hall (1976) are capturing the degree to which communication is based on facts and statements. Logical, linear, actions are used in low-context cultures; logic and decision making are valued based on facts rather than intuition (Agourram, 2013). In low context cultures interactions are formal, expressionary and more direct (Meeuf, 2014). Research shows that cultures of low context such as the US use social media more often than Singapore, a culture of high context. People in the United States tend to post more pictures of themselves on Facebook whereas people from India tend to post pictures that capture public figures (Sharrock, 2013).

Many of the Asian cultures such as Japan, China, and Arab are classified as high-context cultures. On the other hand, Western cultures such as German, Switzerland and United Kingdom are among the low-context cultures in Hall's context. Hall investigated nonverbal components of cross-cultural communication. He defines context in one sense as "one of many ways of looking at things". Dervin defines context as "every possible attribute of person, culture, situation, behaviour, organization, or structure" and "a necessary source of meaning" (Dervin, 1997).

A high-context communication or message is one in which most of the information is already in the person, while very little is in the coded, explicit, transmitted part of the message. A low-context communication is just the opposite; i.e., the mass of the information is vested in the explicit code. In other words, low-context messages are analytical, explicit, and clearly articulated, whereas high-context messages are perceptive, indirect, and ambiguous.

Hall suggests that societies serve a screening capacity, by deciding on what the individuals care for and what they disregard. Individuals in specific societies vary in how much they take care of context information, that is, 'the information that surrounds an event and is inextricably bound up with the meaning of that event'. As indicated by Hall and colleagues, implications can be characterized by that which is as a rule specifically expressed and its specific context; in a high context societies. For instance, in Middle East, the context of the message is more vital than the specifically expressed words, though in a low context society, for example, the United States, the specifically expressed words are more essential than is the unique situation. This high and low context social difference reflects holistic and analytic processing orientations. Literature portraying both these sorts of subjective orientations reliably recommends that Arabs give careful consideration to context than do low context societies like Scandinavians. 


\subsection{Individualist vs Collectivist Cultures}

Different cultural approaches have been subject for various researches in attempt to explain the effect of culture on communication styles (Han, 1994; Zhang, 1996). In his study Hofstede proved that individualistic and collectivistic orientation has a distinctive effect on the way people communicate (Hofstede, 1984). Individualism and collectivism are defined as the degree of people's belonginess or integration into groups. Main individualistic countries are found in North America and Western Europe while collectivism found in Asian and Latin American countries are Hofstede's cultural framework has been a subject for many researches in communication studies (Hofstede, 1976; Kim et al., 1994). Previous studies found strong connections and between the cultural orientation and marketing communications (Albers, 1996; Cho, 1999). Cross cultural researches mainly focused on the individualistic vs collectivistic dimension either as a moderator as a predictor behavior to determine the preferences in social interaction. (Han, 1994; Kishiya, 2015). Besides the wide support, Hofstede's study got also criticism by scholars. Most of the critics were pointed at the methodology and the aged data in his study. (Huang, 1995; Myers, 2002; Smith, 1997). Another line of studies tried to explain the impact of culture on the communication style by connecting two cultural theories. Lee and Choi stated that in individualistic cultures the communication is tend to be more low context whereas in high context cultures the communication tend to be more towards high context communication (Lee \& Choi, 2006). With the new industrial 4.0 era, researchers started to connect the Hofstede's framework with the variables such as content analysis, website effectiveness, social media preferences etc (Chau, 2202; Singh, 2004). In their study Ka confirmed that the cultural differences play a role both at an individual level and on national-level ( $\mathrm{Na}$ et al., 2015).

\subsection{Social Media and its Characteristics}

In 2008 Jason Fallas, the founder of "Social Media Club" company, asked people following this club in twitter to define social media in two or fewer words. The incoming answers defined social media generally as; getting connected, interaction, and social media based on societies/communities, bringing out mass participation and mass connection (Solis, 2009).

The characteristics of social media can be listed as follows:

Participation: Social media eliminates the distance between followers-listeners and the media by encouraging participation and feedback of the people interested in the media.

Openness: Most social media services are open to participation and feedback. These services encourage people to write comments and share information.

Speaking: While the content of traditional media is given one-way to listeners, viewers or readers, social media is known as two-way since it contains feedbacks and comments from participants.

Groups: Individuals forming groups in social media environment communicate effectively with one another They share photographs, political topics and favorite TV shows that are interesting for them among themselves.

Being connected and forming an online culture: The reason for most social media forms to develop/thrive is that they relate to other web sites, sources and people. Social media is related to sociology rather than technology. Sociology presents people the understanding of how social powers form individual behaviors and manners of people. Sociologists control society and social studies using the instructions formed by the groups and individuals within the society Whereas, in social media this control consists of social networks and societal groups within them. Individuals establish their cooperation and commitments within the framework of contents, topics, products, services and thoughts/ideas. The ways they establish relations depend on means and Networks they utilize, and the culture they are in. (Wu, 2007) Social media users form new contents and share them. These users create social cultures on social Networks and they use social instruments/means in order to stay connected with social Networks. In social media every aspect of the media, beginning with the formation of contents to their reading and sharing is a social situation, and as in every social situation, it is necessary to be respectful towards the rules in order to join the groups and take part in their activities (Europe Social Group, 2012). According to Breakinridge, when the base formed by social media is applied to communication programs, it increases awareness, correct responsibility, efforts and humane communication without any difficulty and thus paves the way for humanely communication ( $\mathrm{Wu}, 2007)$. This is a media which has been designed to spread through social interaction. One of the greatest and remarkable properties of social media is that it makes humans and communication humane. The human nature of communication can be explained by the fact that companies talking with their customers instead of conducting marketing (Solis, 2010). Social media enables people producers of contents rather than consumers of content and it supports democratization of information. Wu et al. 
(2018) mentioned that the collectivism has contributed much to social bonding and human wellness.

Formation of Content in Media: Forming content in media is not limited to only journalists, reporters and organizations small or big and public or private. Anybody with an average computer knowledge, can share his ideas, experience, Picture, video and everything he creates with others. In recent years, the contents created by social media users can fill even traditional media contents.

Formation of New Action Groups: With the democratization of the media, the users of social media are known as New Action Groups. This new group, completes the existence of professionals and traditional journalists. These users of social media are considered equally important as journalists and sometimes even more reliable and important than journalists. Social media places media in a public medium and invites public relations not to market but to talk and participate. Social media, by halting the broadcast of public relation experts and by pushing them to get connected with their customers is changing monologue to dialogue and thus attributing new and very important roles to public relations. Indeed, social media is attributing new and very important roles to public relations. It stops them from broadcasting public relations through only radio, TV or newspapers and it presents technologic devices for them. Zhang and Weng (2019) affirm that this given its major transformations in recent decades. Social media is interpreted to change monologue into dialogue.

\section{Research Methodology}

The understanding was sought by taking a holistic approach, rather than looking at a set of variables (Denzin, 2016). Literature was methodically reviewed in the following specialized database sources: Web of Science, PubMed, EBSCOhost, and ERIC. Additionally, Google Scholar searches were performed. The "snowball" method of using the most recent works to find relevant articles cited in them provided additional articles. It was adopted the three most relevant database according Table 1.

Table 1. Bibliometric Search for Theoretical Framework

\begin{tabular}{ccccc}
\hline $\begin{array}{c}\text { Publication } \\
\text { Timeline }\end{array}$ & Items & $\begin{array}{c}\text { Number of Articles } \\
\text { Web of Science }\end{array}$ & $\begin{array}{c}\text { Number of Articles } \\
\text { Google Scholar }\end{array}$ & $\begin{array}{c}\text { Number of Articles } \\
\text { PubMed }\end{array}$ \\
\hline $1990-2019$ & High context, low context, social media & 0 & 1.750 & 2 \\
$1990-2019$ & Individualism, collectivism, social media & 43 & 11.500 & 1 \\
$1990-2019$ & Participation, groups, social media & 836 & 290.000 & 133 \\
$1990-2019$ & Mindset, social media & 161 & 45.700 & 5 \\
$1990-2019$ & Communication and social media & 22.292 & 1.330 .000 & 2.317 \\
\hline
\end{tabular}

\section{Theoretical Framework}

It is important to know the social media characteristics. Yet they are somehow connected to each other. The author would like to propose the circle below, see Figure 1.

The circle suggests that, the speaking between groups can only be via communication. This communication is virtual, via social media networks. Participation of people in social networks is not useful for a marketer unless they give feedback. When the people express their idea, what is wrong or right with the social media tool, the organization can use this feedback to develop better sites. Groups that are gathered in social media are free to express any idea thanks to the feature of sharing. In web portals there are no limitation for people to speak up whether is a profit or nonprofit organization. In order to create an online culture, there is a necessity of direct response from companies and users. If people want to form a new action group for a cause they need to be aware of the culture. To create the content public relations should handle the necessary info and infrastructure. Lastly, all the creation process require creativity. Moreover, all the characteristics are connected to each other with wisdom of crowd and mindset. The wisdom of crowds is a term coined by James Surowiecki to refer to the situations where tapping the knowledge and judgment of many people can produce more accurate results than asking a small group of experts. Surowiecki argues that in some situations, the many can be smarter than the few - a position traditionally at odds with perceptions of crowd behavior (Surowiecki, 2008). Many of these ideas are being tested in practice by large-scale collaboration projects such as Wikipedia, and they underpin much of the theory of web 2.0. In collectivist cultures, the main idea behind the success is based on wisdom of crowd. In addition, mindset means the general understanding or view of an individual, group, or population of people, 
especially as it applies to technology adoption. It is the way we see the world, and the way we approach problems - and solutions. In closing, the conceptual framework suggests that all organizations should analyze these features in advance. Before creating a networked organization they need to understand the relation between social media and its characteristics and their relation to culture. Together with the cultural context, these features are crucial while creating an online marketing communication plan.

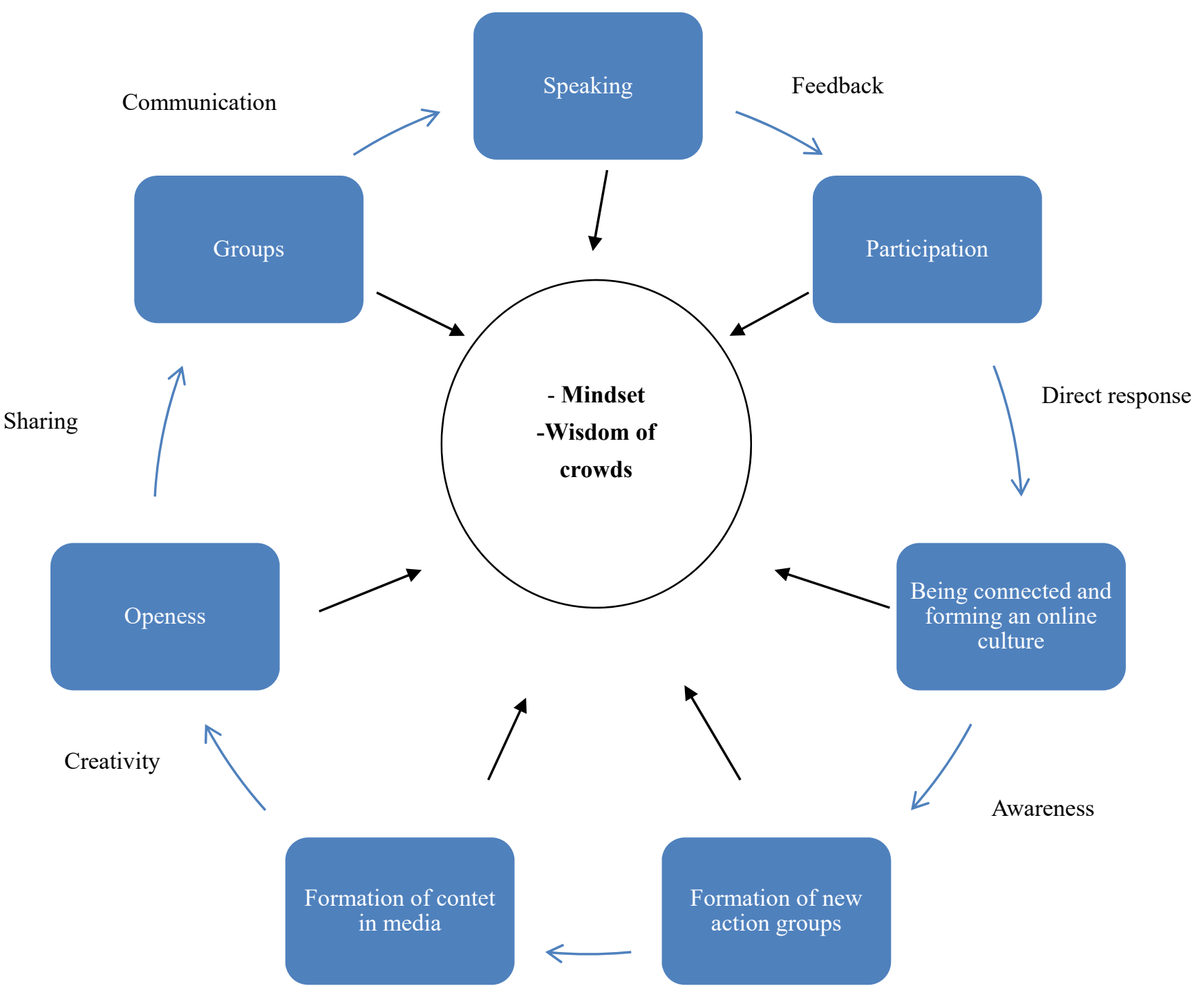

Public Relations

Figure 1. Interrelation between Social Media Characteristics (Developed by the authors)

\section{Conclusions and Research Limitations}

This research aims to point out the gap in analysis between cultural factors and media allocation. So far little is known about how consumers from diverse cultures process visual images. (Mooij, 2018). Understanding cultural factors play a key role in media selection. The bibliometric when applied to the Google Scholar is not select just papers, but innumerous other sources, such as books, webpages and amateurs' publications, out of the academic spectrum. Even in the academic data base the numbers are restrict about the areas investigated by this paper and futures studies are required to explore this field.

Despite the conclusions about links between culture and social media, this research presents certain limitations with respect to theoretical questions, as well as to methodological issues. The study findings need to be understood according to its limitations. First, the research heavily relies on the secondary data. 
Second, this paper tries to create a linkage between some cultural elements, social media and wisdom of crowds. The linkage can be much broader and the conclusions drawn can be more validated with a data set.

Facebook and WhatsApp are the dominant social media platforms in the region, about eight in 10 national internet users use these two platforms ( $82 \%$ and $77 \%$ respectively). We can learn a lot about cultural standards of technology and gender through such platforms. Also, representation of the gender can give important information for an understanding of social media and the corporate promotion for which social media is often used. While undertaking social media studies, it is important to understand the role of promotion in the current development of our comprehension of platforms such as Twitters and their economic, political and cultural effects.

\section{References}

Agourram, H. (2013). The impact of national culture on online social network usage and electronic commerce transactions. European Scientific Journal, 9(19).

Al-Jenaibi, B. (2011). The use of social media in the United Arab Emirates-an initial study. European Journal of Social Sciences, 23(1), 84-97.

Aladwani, A. M. (2003). Key Internet characteristics and e-commerce issues in Arab countries. Information Technology \& People, 16(1), 9-20. https://doi.org/10.1108/09593840310462998

Arab Social Media Report 2013. ASMR in the media. Retrieved fromhttp://www.arabsocialmediareport.com/home/index.aspx

Arab Social Media $\quad$ Report $2015 . \quad$ Retrieved https://www.wpp.com/govtpractice/ /media/wppgov/files/arabsocialmediareport-2015.pdf

Arab Social Media Report 2017. $\quad$ Retrieved from https://www.wpp.com/govtpractice/ /media/wppgov/files/arabsocialmediareport-2017.pdf

Breakenridge, D. K. (2008). PR 2.0: New media, new tools, new audiences. FT Press.

Britt, S. H. (1974). Standardizing marketing for the international market. Columbia Journal of World Business, 9(4), 39-45. https://doi.org/10.1016/0969-5931(96)00020-0

Denzin, N. K., \& Giardina, M. D. (Eds.). (2016). Qualitative inquiry and the conservative challenge. Routledge.

Dervin, B. (1997). Given a context by any other name: Methodological tools for taming the unruly beast. Information seeking in context, 13, 38.

Europe Social Group. (2012). Is Pinterest the Next Big Social Network in Europe? Retrieved from http://www.comscoredatamine.com/2012/02/is-pinterest-the-next-big-social-network-in-europe/

Hall, E. T. (1966). The hidden dimension. New York: Anchor Press/Doubleday.

Hall, E. T. (1976). Beyond culture. New York: Anchor Press/Doubleday.

Howard, P. N., \& Hussain, M. M. (2011). The role of digital media. Journal of democracy, 22(3), 35-48. https://doi.org/10.1353/jod.2011.0041

Kaplan, A. M., \& Haenlein, M. (2010). Users of the world, unite! The challenges and opportunities of Social Media. Business Horizons, 53(1), 59-68. https://doi.org/10.1016/j.bushor. 2009.09.003

Mataruna, L., \& Pena, B. (2017). Mega Events Footprints - past, present and future. Rio de Janeiro: Engenho.

Meeff, K. (2014). Regional Use of Social Networking Tools. Retrieved from http://repository.cmu.edu/cgi/ viewcontent.cgi? article $=1818 \&$ context $=$ sei

Mooij, M. (2013). Global Marketing and Advertising Understanding Cultural Paradoxes (3rd ed.). Sage Publications.

Milla, A. S. C., Mataruna, L., \& Ristic, M. R. (2018). Adopting Social Media for Nonprofits as a Main Marketing Tool: Analysis of a Youth Non-Profit Organization. International Journal of Applied Business and Economic Research, 22(2).

Na, J., Kosinski, M., \& Stillwell, D. J. (2015). When a new tool is introduced in different cultural contexts: Individualism-collectivism and social network on Facebook. Journal of Cross-Cultural Psychology, 46(3), 355-370. https://doi.org/10.1177/0022022114563932

Obermeyer, C. M., Bott, S., \& Sassine, A. J. (2015). Arab adolescents: health, gender, and social context. Journal of Adolescent Health, 57(3), 252-262. https://doi.org/10.1016/j.jadohealth.2015.01.002 
Salem, F. (2017). The Arab Social Media Report 2017: Social Media and the Internet of Things: Towards Data-Driven Policymaking in the Arab World (Vol. 7). Dubai: MBR School of Government.

Sharrock, J. (2013, January 31). How Facebook plans to make us all get along. Retrieved from http://www.buzzfeed.com/justinesharrock/ how-facebook-plans-to-make-us-all-get-along\#.mcnYE6AD0

Solis, B. The Essential Guide to Social media. Retrieved from http://www.onecaribbean.org/content/files/essentialGuidetoSocialMedia.pdf

Solis, Braian ve Breakenridge, Deirdre. (2009). Putting the Public Back in Public relations. New Jersey: FT Press.

Sundaram, A. (2017). Leveraging Social Media for Development in Organizations. Asian Social Science, 13(4). https://doi.org/10.5539/ass.v13n4p201

Surowiecki, J. (2004). The Wisdom of Crowds. USA: Doubleday.

Trends in UAE's social media usage revealed. (2017) Retrieved from http://www.thenational.ae/uae/technology/20170130/trends-in-uaes-social-media-usage-revealed

Wu, J. H., Chen, Y. C., \& Lin, L. M. (2007). Empirical Evolution of the Revised End User Computing Acceptance Model. Computers in Human Behavior, 23, 162-174. https://doi.org/10.1016/j.chb.2004.04.003

Wu, M. S., Zhou, C., Chen, H., Cai, H., \& Sundararajan, L. (2018). Cultural value mismatch in urbanizing China: A large-scale analysis of collectivism and happiness based on social media and nationwide survey. Int $J$ Psychol., 53(Suppl 2), 54-63. https://doi.org/10.1002/ijop.12523.

Zhang, R., \& Weng, L. (2019). Not all cultural values are created equal: Cultural change in China reexamined through Google books. Int J Psychol., 54(1), 144-154. https://doi.org/10.1002/ijop.12436

\section{Copyrights}

Copyright for this article is retained by the author(s), with first publication rights granted to the journal.

This is an open-access article distributed under the terms and conditions of the Creative Commons Attribution license (http://creativecommons.org/licenses/by/4.0/). 